\title{
DE NUEVO ACERCA DE LA VILLA ROMANA DE ALMENARA DE ADAJA (VALLADOLID): EXCAVACIONES DE 1998 A 2002
}

\author{
POR \\ CARMEN GARCÍA MERINO \\ MARGARITA SÁNCHEZ SIMÓN \\ Universidad de Valladolid
}

PALABRAS CLAVE: Villa romana. Cronología. Estratigrafía. Arquitectura. Salas de recepción. Balneum. Mosaicos. Bajo Imperio.

KEY WORDS: Roman Villa. Cronology. Estratigraphy. Architecture. Reception rooms. Baths. Mosaics. Late Empire.

\section{RESUMEN}

-Se hace un avance de la información obtenida en las excavaciones realizadas entre 1998 y 2002 en la villa de Almenara. Se trata acerca de la cronología y de la planta de su pequeño palacio de $2.500 \mathrm{~m}^{2}$ exhumado por completo. Se analizan sus cinco grandes espacios de representación y el balneum donde tuvieron lugar importantes reformas y se da a conocer un nuevo mosaico.

\section{SUMMARY}

Information obtained from the excavations made in the roman villa at Almenara-Puras (Valladolid) from 1998 to 2002 is summed up. We deal with cronology and structure of its small palace, occupying a surface of $2.500 \mathrm{~m}^{2}$ and which has been completely uncovered. Five large representation areas and the balneum which was subjected to important remodelations are analyzed and a new mosaic is presented.

\section{INTRODUCCIÓN}

En julio de 2002 el área residencial de la villa romana de Almenara de Adaja-Puras (Valladolid) ha quedado totalmente descubierta. Para ello ha sido necesario abordar un proyecto conjunto de excavaciones, consolidaciones y restauración de estructuras que, desde 1996, se han llevado a cabo mediante Convenios renovados anualmente entre la Diputación Provincial y la Universidad de Valladolid bajo nuestra dirección ${ }^{1}$. Este proyecto ha hecho posible finalmente, la puesta a punto para la visita de un yacimiento conocido desde el siglo XIX y donde en distintos momentos se habían realizado excavaciones sin continuidad, a cargo de diferentes

\footnotetext{
${ }^{1}$ Forman parte de este equipo, entre otros, Milagros Burón y Rosario Suárez, que han codirigido algunas campañas de excavaciones, y Giacomo Gillani.
}

equipos ${ }^{2}$. El proyecto, que ha debido superar los problemas que intervenciones realizadas en varias épocas plantean a la hora de abordar una labor global de investigación y recuperación de un yacimiento, se ha desarrollado en tres vertientes: estudio arqueológico, restauración y puesta a punto de la villa para su exposición al público ${ }^{3}$.

Se procedió en primer lugar a delimitar y proteger el área de $4.800 \mathrm{~m}^{2}$ donde se iba a intervenir y a redactar un Plan Director que definía los objetivos y establecía las diferentes actuaciones a desarrollar $^{4}$.

Lo que se conocía hasta entonces del yacimiento era parte de la zona residencial de una villa pavimentada con mosaicos. Para completar la planta del edificio y obtener información sobre ella ha sido preciso excavar los $4.880 \mathrm{~m}^{2}$ de la zona cercada. Ese trabajo ha supuesto la re-excavación de la parte ya conocida de la villa, aproximadamente el $60 \%$ de la vivienda del propietario, sacada a la luz en excavaciones anteriores semi-enterradas de nuevo, la eliminación de numerosos pasillos-testigo de viejas campañas y excavar hasta la tierra virgen lo intacto. Además, ha sido necesario excavar al exterior de la zona cercada los $1.000 \mathrm{~m}^{2}$ de terreno afectados por el Museo/Centro de información anejo. Paralela-

${ }^{2}$ En la villa se iniciaron las excavaciones en 1942 por G. Nieto y continuaron luego de forma intermitente, dirigidas, entre otros por A. Balil y T. Mañanes.

${ }^{3}$ En lo que se refiere a la investigación, los problemas son la falta de documentación e información sobre la estratigrafía, los materiales, etc. de la mayoría de las campañas de excavación. En cuanto a la restauración, aunque también se habían llevado a cabo algunas consolidaciones de muros y mosaicos en los años setenta, el mal resultado de ciertos materiales empleados, el retraso en la puesta a cubierto de las habitaciones exhumadas y los diferentes criterios de actuación han obligado a partir de cero en las últimas intervenciones y han acarreado la pérdida de una parte apreciable de algunos mosaicos.

${ }^{4}$ Se cerró el espacio a intervenir con una estructura rectangular con celosía de madera en tres lados y pared de cristal en otro, y se cubrió con bóvedas de chapa nervada lacadas en blanco, según proyecto del arquitecto Roberto Valle González, coautor del Plan Director y autor del proyecto del Centro de Información-Museo de las villas romanas. 
mente se ha procedido a restaurar los mosaicos, sometidos hace más de treinta años a una consolidación que se ha revelado más perjudicial que eficaz, así como los pavimentos de opus signinum y los muros. Finalmente se han acondicionado para la visita los restos construidos en el siglo IV.

En conjunto, las diversas campañas que hemos realizado han puesto al descubierto toda la residencia del dueño y parte de la zona de servicios e instalaciones anejas de la explotación agropecuaria de una villa de los siglos IV y v. Además, se han exhumado restos de una parte de los baños y zonas de almacenamiento de una villa anterior. También se ha excavado al exterior de las termas el borde de un gran vertedero sobre el que se levantó el sector occidental de la villa, muy interesante para comprender la cronología de ésta.

Por su parte, las intervenciones practicadas al sur, en la zona del Museo, han servido para conocer la historia arqueológica del yacimiento. Han proporcionado abundantes materiales cerámicos pre y protohistóricos, materiales romanos altoimperiales y muros y recipientes de almacenamiento de las instalaciones de la pars rustica de la villa que precedió a la bajoimperial. También se han documentado aquí instalaciones de la explotación rural correspondientes a esta última reducidas sólo a cimentaciones por tratarse de la zona más elevada del yacimiento, donde los últimos niveles arqueológicos están arrasados por las labores agrícolas.

Como resultados inmediatos de las excavaciones, cuyo segundo avance damos en estas notas, en espera de que finalice el estudio global de las últimas campañas y se recojan los resultados en un volumen monográfico, se pueden citar, ciñéndonos a la época romana, entre otros, los siguientes:

- La exhumación completa del edificio residencial de la villa de los mosaicos cuya superficie alcanza así los $2.500 \mathrm{~m}^{2}$, un aumento apreciable respecto a lo ya conocido.

- La confirmación de su fábrica de nueva planta en el s. IV y su abandono como residencia en el v.

- La mayor extensión y complejidad de los baños, donde se han constatado importantes reformas.

- La aparición de un nuevo mosaico y la exhumación completa de tres de ellos que se conocían solo parcialmente, tal es el caso del pavimento del oecus octogonal cuyo emblema figurado trata un tema mitológico.

- El conocimiento de una serie de estructuras correspondientes a las instalaciones de las partes fructuaria y rustica.

- La documentación de una villa previa, no ya a través de materiales, sino también de estructuras co- herentes que corresponden a la pars urbana — parte del balneum (fig. 1, C y fig. 2) - y a la pars rusti$c a$ : restos de la zona de almacenamiento y la solera de un horno (fig. E y D respectivamente).

\section{ACERCA DE LA SECUENCIA CRONOLÓGICA DEL YACIMIENTO}

\section{ANTES DE LA VILLA}

En el solar que con el tiempo ocuparía la villa, se han hallado evidencias de actividad humana desde el Calcolítico. Son particularmente interesantes las cerámicas calcolíticas con bellos ejemplares de vasos decorados y algún depósito que se puede poner en relación con el cercano yacimiento de Fuente Olmedo. Asimismo, materiales de la Edad del Bronce y del Hierro I e, incluso, tardoceltibéricos ${ }^{5}$, todos los cuales aparecen generalmente fuera de su contexto original.

En lo que respecta a la ocupación de época romana, los escasos materiales publicados anteriormente ofrecían una amplia panorámica desde el siglo I al v. La datación de la villa de los mosaicos en el siglo IV, propuesta por Mañanes - origen en el siglo III, esplendor en el IV y abandono en los inicios del V (Mañanes, 1993, 51) - se hizo con base en la cronología de los materiales predominantes y en el estilo de los mosaicos. En las excavaciones realizadas en el marco del proyecto de recuperación, no solo se han documentado materiales en esa misma línea sino también estructuras con un registro estratigráfico claro. En cuanto a los materiales, mayoritariamente cerámicos, proceden de un vertedero sobre la ladera que al oeste del yacimiento desciende al charcal o bohodón denominado el Arroyuelo. También se han encontrado en los niveles previos a la villa bajoimperial donde había bastante cerámica, pero casi siempre en posición secundaria. Esos depósitos han proporcionado evidencias de la ocupación del lugar desde el siglo I hasta muy entrado el siglo $\mathrm{V}$. Por otra parte, la existencia de materiales desde época julio-claudia parece apuntar a una ocupación continuada del lugar, es decir a que no hubo abandono entre el hábitat del siglo I y la villa del siglo IV, al contrario de lo que, a falta de información suficiente, se ha sugerido en alguna ocasión (Balado, 1987, 178). Sin embargo, al menos por ahora, no tenemos

\footnotetext{
${ }^{5}$ Para los materiales pre y protohistóricos hallados en las excavaciones de los años 70 y 80 véase A. Balado, 1987. Para un avance de los correspondientes a las excavaciones de 1999 y 2000 García Merino y Sánchez Simón, 2000. Para los de 2001 y 2002, Delibes y Guerra (en preparación).
} 


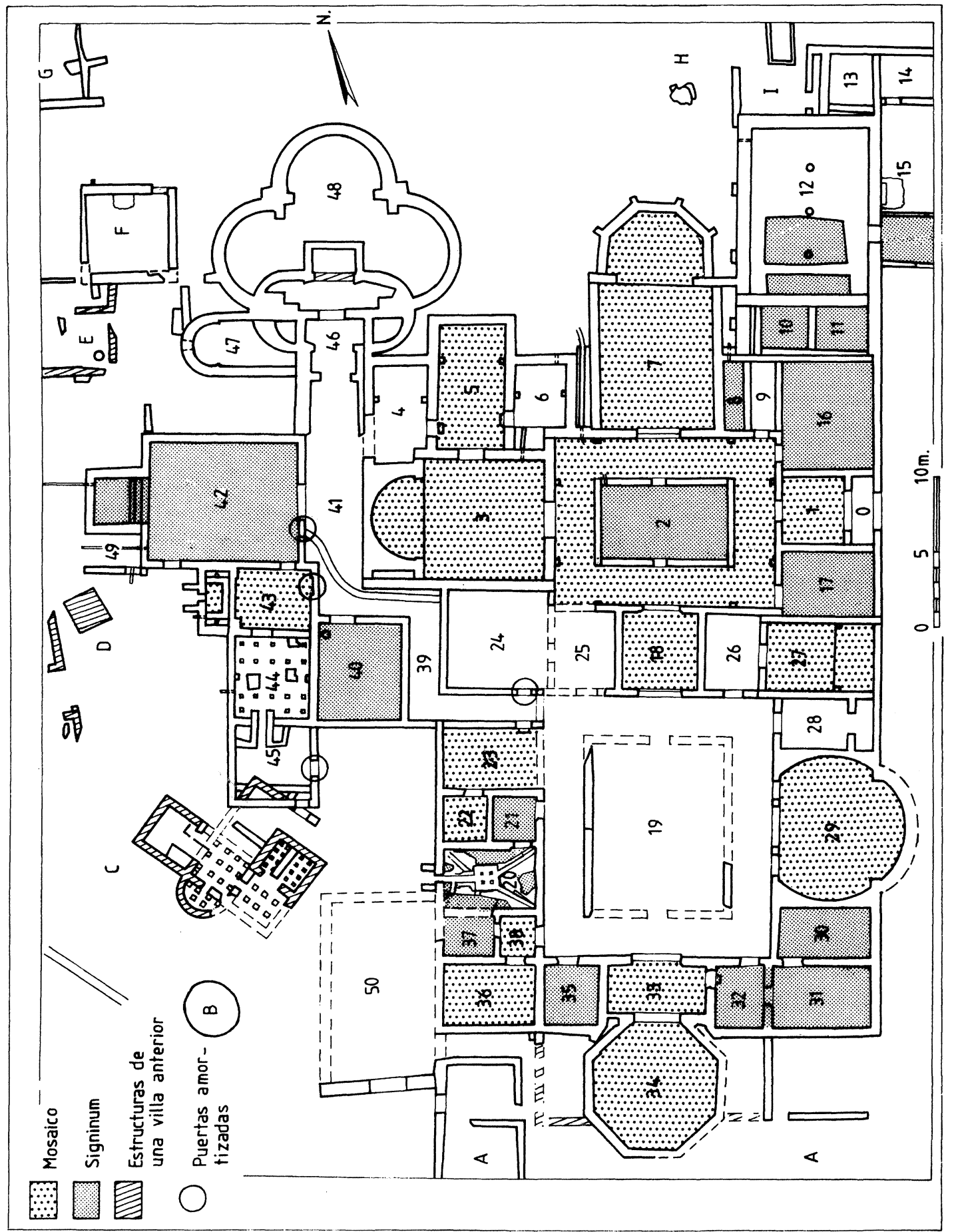

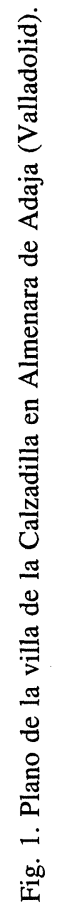




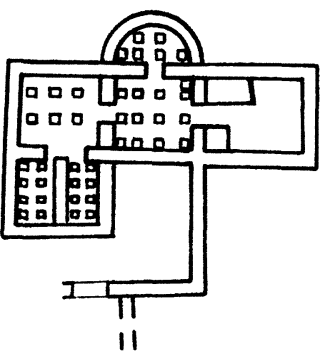

1

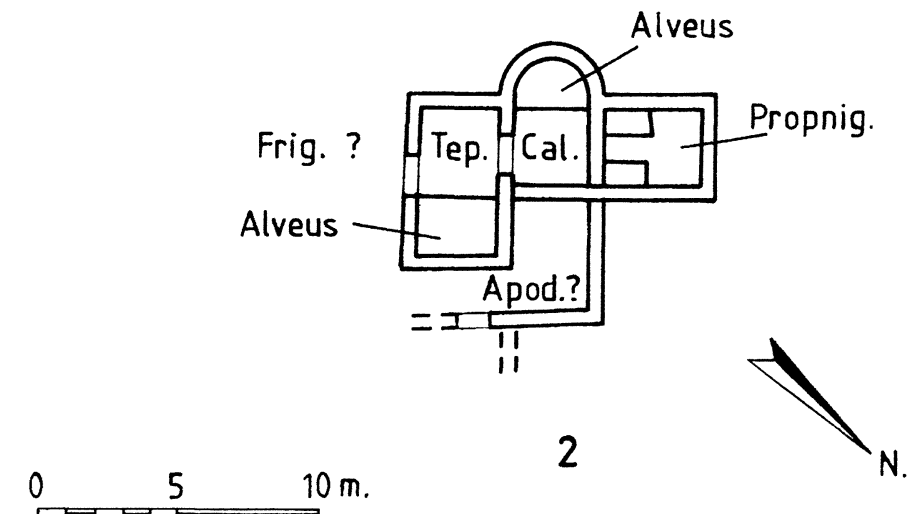

Fig. 2. Estructuras de una villa previa a la conocida como de Almenara.

datos suficientes para afirmar que ya hubiese aquí una villa en tan temprana fecha. Es posible, pero la certeza de su existencia, como tal villa, no se puede llevar más allá de la tercera centuria.

\section{UNA VILLA PREVIA A LA DE LOS MOSAICOS}

Antes de que se levantara la mansión de los pavimentos musivos que conocemos como villa de Almenara, una domus dominica se alzaba en este mismo paraje y, lo mismo que ella, se construyó parcialmente (en su borde oeste) sobre el depósito que durante dos siglos ${ }^{6}$ los habitantes del lugar habían ido formando con vertido de desechos sobre la pendiente natural hacia el labajo del Arroyuelo, ganando terreno sobre el declive.

En efecto, el hallazgo de estructuras coherentes por debajo de la villa de los mosaicos permite afirmar que hasta entrado el siglo IV (no se puede precisar desde cuando, pero tal vez ya en el II), existía aquí una villa con su edificio residencial dotado de baños, y unas instalaciones de almacenamiento, elaboración de alimentos y áreas de trabajo, propias de una explotación agrícola.

Seguramente la pars urbana tenía menor extensión que la correspondiente de la villa bajoimperial ya que, al menos toda la parte occidental de ésta (los baños), se levanta sobre dependencias de almacenamiento - recintos delimitados por muros de cantos rodados con dolias incrustados en el suelo- y trabajo - solera de horno, canalizaciones y murosde su pars rustica (fig. $1 \mathrm{D}$ y E respectivamente). La orientación de los muros de ambas es la misma pero

${ }^{6}$ Los materiales contenidos en este vertedero son muy abundantes y tienen sus exponentes más antiguos en la sigillata itálica. Sobre parte de ellos puede verse García Merino y Sánchez Simón, 2000, 110 y 117-119. la más antigua tuvo su balneum en un pabellón aparte, con una alineación oblicua a la casa, algo frecuente en el siglo III. Los muros, construidos en opus caementicium de excelente calidad, delimitan un propnigeum con praefurnium tipo III de Degbomont, y dos hipocaustos intercomunicados. Estas cámaras de calor, que se hallaron en la campaña de excavaciones de 2001, corresponden a un caldario cuadrangular absidado con alveus en la cabecera y a un tepidario rectangular con otro baño (fig. 1, C y fig. 2).

\section{CRONOLOGÍA DE LA CONOCIDA COMO VI- LLA DE ALMENARA}

\section{ASPECTOS ESTRATIGRÁfiCOS DEL EDIFICIO SE- ÑORIAL}

En el interior de la casa no afectado por excavaciones anteriores, la estratigrafía en las habitaciones con suelo de mosaico o signinum es muy sencilla: hay bajo el nivel superficial un nivel de derrumbe de la construcción directamente sobre los pavimentos. Este nivel contiene materiales de muros y techumbre. La estratigrafía del cubículo $n^{\circ} 22$, donde ha aparecido un nuevo mosaico en extraordinario estado de conservación, es muy ilustrativa a este respecto ${ }^{7}$.

\footnotetext{
${ }^{7}$ Bajo el nivel superficial había un nivel de derrumbe de morteros entre 20 y $25 \mathrm{~cm}$ de potencia, con cinco placas de revestimiento parietal relativamente grandes que levantaron los restauradores, y de las que solo dos se pueden relacionar con una pared, la sur; el material asociado a este nivel es escaso y poco significativo tipológicamente. Son fragmentos de terra sigillata y cerámica común, y, sobre todo, cerámicas a mano, de pastas oscuras y granulosas. Por debajo, sobre el mosaico, estaba el nivel de derrumbe de la techumbre, que contenía básicamente teja curva y se extendía en una franja de 1/1,30 m de ancho en el centro de la habitación.
} 
La extracción de materiales constructivos de la villa ha sido muy intensa en todo el edificio, y no se ha producido en un solo momento. En algunas zonas donde se han documentado zanjas de expolio los muros fueron deshechos hasta su mismo asiento pero, incluso donde no se han visto esas zanjas y los muros de mampuesto de caliza y mortero rematan en superficies planas a 30 ó $40 \mathrm{~cm}$ del suelo hay pocos restos del alzado que falta. Las tejas en algunos puntos no son tan abundantes como cabría esperar si nada hubiera alterado la formación del depósito, lo que indica un expolio muy temprano. Es decir que la parte de las tejas, el maderamen de las cubiertas y parte de los muros fueron retirados antes del derrumbamiento del edificio - con la consiguiente pérdida de los revestimientos parietales-, antes de los procesos deposicionales que han formado el yacimiento. Mucho después se practicaron sobre él grandes zanjas para acceder a las ruinas y reaprovechar todo lo posible piedra, tejas y ladrillos. Así en la habitación $n^{\circ} 20$ una gran trinchera rompió el suelo de signinum para retirar los elementos latericios del hipocausto, además de tejas y la losa del umbral. Sin embargo, en otros puntos de la casa los niveles asociados con su destrucción presentan abundante material constructivo y también cerámica común, terra sigillata tardía y algunas cerámicas a mano de pastas toscas, porosas, de corte granuloso, con desgrasante de cuarzo, en tonos pardos o negros, con formas de cuenco y recipientes con tapadera.

\section{LA SECUENCIA CRONOLÓGICA DE LA VILLA DE LOS MOSAICOS}

La acusada escasez de materiales de diverso tipo, esperables en un contexto de hábitat como éste, señalada ya por G. Nieto $(1942-43,198)$ y comprobada por nosotros en las excavaciones de la zona exhumada ex novo, unida al hecho de que se está estudiando aún el material de las dos últimas campañas, dificulta por ahora el establecimiento de una secuencia temporal matizada para la villa. Con todo, se puede avanzar que en las últimas excavaciones, la secuencia estratigráfica nos ha deparado algunos datos que sirven para la datación relativa de la villa. Así hay unos materiales que sirven como terminus post quem para la construcción de la casa y otros como post quem para su destrucción.

Los elementos utilizables como términos post quem de la villa de los mosaicos, son tres monedas halladas en la zona norte de la villa, en unidades estratigráficas previas a su construcción:

- Bronce de Licinio (308-324) bien conservado, con reverso de Soli Invicto Comiti (RIC, IX), en el nivel de escombro, previo a la construcción de la gran sala trícora, cortado por las zanjas de cimentación de ésta. Por debajo no han aparecido otros niveles arqueológicos. Considerando la probable larga circulación de esa pieza se puede pensar que la trícora se hizo, sin duda, después de 308 y posiblemente a partir de la segunda mitad del siglo IV. Dado que esta sala es el elemento más tardío del conjunto pues todo parece indicar que se levantó después que el cuerpo principal del balneum, y considerando la cronología de su planta cuyos paralelos se fechan a partir de finales del siglo IV o, incluso, a comienzos del siglo $\mathrm{V}$, no hay que descartar para esta parte del edificio un contexto temporal teodosiano.

- Bronce de Constantino (306-337) de la ceca de Tréveris, con reverso de Soli Invicto Comiti y PLC en exergo (RIC, IX), perteneciente a una unidad estratigráfica equivalente a la anterior. Fue hallada al exterior de la casa, en la zona rústica y fructuaria.

- Bronce de Galerio Maximiano (294-296?) de Tréveris, con reverso Fel reparatio temporum, genio en pie a la izquierda sacrificando con pátera y cornucopia y PLC en exergo (RIC, IV), en un nivel correspondiente al uso de las estructuras de la pars rústica de la villa previa.

Por ello, se puede afirmar que la villa de los mosaicos se construyó, como pronto, a mediados del siglo IV y, por lo dicho al principio, que se edificó, al menos las habitaciones meridionales y en particular la esquina sudoeste (fig. 1), sobre los restos demolidos de otra anterior, de la que han aparecido en otros puntos del solar parte de las instalaciones de almacenamiento.

Como terminus post quem o ante quem non, hay cerámicas grises estampadas en el nivel de destrucción del edificio, es decir que el abandono no se produjo antes de la segunda mitad del siglo v.

En definitiva, y hasta que el estudio del conjunto del material de la campañas de 2001 y 2002 esté ultimado, parece claro que el área del balneum se reformó en la segunda mitad del siglo IV y que la sala triconque se añadió a finales de esa centuria o comienzos de la siguiente. Por tanto, la zona residencial estaría en uso hasta finales del siglo $\mathrm{V}$ o comienzos del VI, cuando se abandonaría de forma definitiva, sin violencia. Sus últimos ocupantes debieron de marcharse llevando consigo todo el ajuar aprovechable. Tal vez los años finales de la ocupación estuvieran marcados por un lento empobrecimiento. Hay algunos datos que apuntan en este sentido: reparaciones de muy baja calidad en el mosaico del tepidario y algunos arreglos en otros de 
la zona sur. Incluso se observan (acaso hechos más tarde) otros que ya no son de tosca factura sino parches, por ejemplo el de la habitación 36 en cuya esquina sudeste se emplearon tortas de mortero para llenar baches. Esos arreglos parecen deberse a los últimos habitantes cuya vinculación con los antiguos dueños es imposible establecer. Por ahora, lo que es claro es que en siglo vi ya debía de estar abandona$\mathrm{da}^{8}$. Las huellas de hogueras, visibles sobre algunos mosaicos, apuntan a que el inmueble en proceso de ruina se utilizó ocasionalmente como refugio y enseguida fue expoliada su fábrica: desmontados sus muros y recogidos ladrillos, tejas y vigas para ser reaprovechados como material constructivo. Todo ello ha determinado una notable escasez de material de construcción y elementos decorativos de la arquitectura en los niveles arqueológicos, parquedad que se suma a la de ajuar doméstico, reiteradamente señalada por los sucesivos excavadores desde 1942, cuando G. Nieto lamentaba la «falta absoluta de ajuar» (Nieto 1942-43, 198).

\section{LA PLANTA DE LA ZONA RESIDENCIAL}

El conjunto arquitectónico destinado a la residencia de los dueños de la villa ocupa, como ya hemos señalado, una superficie de $2.500 \mathrm{~m}^{2}$. Corresponde a la última fase de la instalación hispanorromana. El edificio (fig. 1) no parece el resultado de diversas adiciones a un cuerpo original, hechas a lo largo del tiempo, sino el fruto de un planteamiento homogéneo. Ha sido construido y solado en su mayor parte en una misma época, sin perjuicio de las reformas puntuales que se han observado. Tiene un gran cuerpo rectangular, orientado de noreste a sudeste y claramente estructurado en dos bloques conexos. En uno de los lados largos de ese cuerpo, el occidental, hay un tercer bloque comunicado con los anteriores por un pasillo en zigzag iluminado desde un pequeño patio $\left(n^{\circ} 24\right)$. Las tres partes del edificio están interrelacionadas y es perfectamente manifiesta la circulación interna.

Dos de los bloques, conexos a través de una estancia con dos puertas afrontadas (fig. $1, \mathrm{n}^{\circ} 18$ ) tienen funciones de representación pero también de vivienda familiar, organizados en torno a espacios porticados a cielo abierto, un patio porticado al norte y un peristilo con jardín al sur. El tercer bloque alberga el balneum. Se trata en conjunto de 50 espa-

\footnotetext{
${ }^{8}$ De la posible ocupación de época visigoda que se desprende del comentario de Nieto al pie de la lámina $X$ con un enterramiento, no se ha documentado nada ni en las nuestras ni en las anteriores excavaciones.
}

cios diferentes entre patios, corredores y pasillos, salones, comedores, salas, dormitorios, jardín, dependencias de servicio y recintos fríos, templados y calientes de los baños. El eje mayor del gran cuerpo rectangular tiene en sus extremos sendos ambientes de representación con dimensiones y planta acordes con su cronología bajoimperial: en el eje mayor un salón rectangular con exedra pentagonal y otro octogonal. En ambos patios hay, en posición ortogonal a las salas de representación citadas, otras dos grandes estancias: en el sector norte un gran triclinio cuadrado con cabecera semicircular y en el sur otro con planta ultrasemicircular de contorno interior suavemente triconque.

En los extremos de la fachada, fuera ya de la zona cubierta donde se han desarrollado las intervenciones, se inician una serie de espacios que corresponden al arranque de las dos alineaciones de estructuras documentadas en fotografía aérea ${ }^{9}$ que se extienden transversalmente a la casa, a lo largo de unos $70 \mathrm{~m}$. Esos espacios, lo mismo que algunos suelos de baldosas, una pileta de hormigón hidráulico y un posible horno que se han hallado al norte y oeste en el exterior de la casa, corresponden con probabilidad a las instalaciones de la pars rustica: almacenes, establos, talleres, etc. de la villa.

\section{El sector septentrional del edificio}

Se distribuye a partir de un gran espacio rectangular porticado, orientado transversalmente al eje longitudinal del conjunto. En él desemboca el acceso principal y a él se abren solamente cinco vanos: dos de las estancias que flanquean la entrada, otros dos de piezas de grandes dimensiones, ambas cuadrangulares, una con cabecera poligonal y otra semicircular, y el quinto, abierto a un espacio que comunica la parte norte con la parte sur de la casa

En la fachada oriental se encuentra el acceso principal a la casa (fig. $1, \mathrm{n}^{\circ} 1$ ), ligeramente descentrado y estructurado en dos espacios, las fauces propiamente dichas, con suelo de mortero, y un zaguán o vestíbulo pavimentado con un tapiz musivo en damero de rombos que contienen un motivo cruciforme formado por cuatro flores de lis. El peristilo o patio peristilo (fig. $1, n^{\circ} 2$ ) tiene dos accesos en los lados largos y está bordeado por cuatro galerías soladas con un mosaico que presenta dos variantes: una en las galerías norte y sur y otra en las galerías

\footnotetext{
${ }^{9}$ Fotografias realizadas por J. Del Olmo. En ellas se observan además, a corta distancia de la zona excavada, estructuras que podrían corresponder a otra residencia (al $\mathrm{SO}$ ), a instalaciones rústicas $(\mathrm{al} \mathrm{N})$ y a un edificio de culto (al $\mathrm{S}$ ).
} 
este y oeste. La decoración musiva se adapta al contorno de unas pilastras que enmarcan las puertas centradas en cada lado del patio. El area esta pavimentada con opus signinum y tiene un desagüe para evacuar las aguas de lluvia. Este espacio es de los que se exhumaron en 1942 y luego fueron objeto de una consolidación. Sobre su estado anterior a la restauración sólo existe una fotografía de G. Nieto (Nieto, 1942-43, Lám. II) que nos permite comprobar que la altura que ahora presentan los muros que delimitan el área a cielo abierto es la original, aunque resulta demasiado alta para un peristilo. Esa altura ha llevado a Mañanes (Mañanes, 1992, p. 44) a suponer que sería un patio con arcadas. Se ha considerado también un atrio pero no hay nada que justifique esta interpretación, no ya por el anacronismo de un atrio en esta época, sino porque no tiene los rasgos propios de este tipo de estructura. Además las basas que Nieto halló en el lado este del patio (Nieto, 1942-43, Lám. III) y que consideró pertenecientes a la entrada principal, debían corresponder a ese lado del pórtico y hallarse fuera de su lugar.

Lo que resulta extraño y arcaizante es la proporción de achura entre las galerías y el espacio a cielo abierto, que aquí no es de tres a uno o mayor, sino de dos a uno, con lo que los ambulacros resultan muy anchos y pequeño el espacio descubierto. En cualquier caso, son esa proporción y la presencia de las fauces flanqueadas por dos ambientes casi simétricos que recuerdan las tabernae de las viejas plantas itálicas, los que sugieren la idea de un atrio. El mosaico y las pilastras contribuyen a la prestancia y empaque de la zona de representación.

En el extremo del eje en que se halla la puerta principal, hay un gran salón cuadrangular absidado (fig. 1, $\mathrm{n}^{\circ}$ 3) de $75 \mathrm{~m}^{2}$, que ocupa casi todo ese lateral del patio. Tiene suelo de mosaico (NeiraMañanes, 1998, 20-21, Lám. 8) y se comunica en su lado norte con un grupo de tres habitaciones cuya cabecera esta marcada con pilastras. La central de las tres cámaras, la $\mathrm{n}^{\circ} 5$, es de mayor tamaño, $35 \mathrm{~m}^{2}$, tiene el fondo más elevado, a modo de estrado y se abre a otras dos habitaciones exhumadas también en 1942, (fig. $1, \mathrm{n}^{\text {os }} 4$ y 6), situadas a un nivel más bajo, por sendas puertas estrechas con un escalón de caliza, que no conservan ningún tipo de pavimento y sobre las que apenas hay información. El mosaico de la sala $\mathrm{n}^{\circ} 5$, denominado por Mañanes «de las cuatro guirnaldas», resulta especialmente notable por su armonía y la sintaxis de los motivos que lo componen (Neira y Mañanes, 1998, 21-22; Láms. 24 y 27) ${ }^{10}$. Reúne los elementos más significativos del elenco ornamental empleado en esta residencia. El estrado, con alfombra musiva de peltas, el mismo tema que el fondo del salón de Pegaso indica el carácter noble de la estancia, sin duda destinada a las actividades de representación del dominus.

En el centro del corredor norte una amplia puerta se abre a un salón rectangular con exedra pentagonal reforzada al exterior por contrafuertes. La presencia de contrafuertes en los muros del lado norte se debe probablemente al declive del suelo en esta dirección que da lugar a diferentes niveles en el plano en la casa, salvados por escalones. El peso de los muros y cubiertas en esta zona se incrementaría por el efecto del declive. Todo el sector septentrional del edificio debía soportar mayor carga y fuerzas de empuje que el resto, por lo que hubo que reforzarlo. De ahí que los muros sean más anchos o dobles o se ayuden de contrafuertes exteriores y arcos de descarga en cimentación, como ocurre en la gran estancia triabsidada del área termal (fig. 1, $\mathrm{n}^{\circ} 48$ ).

Este salón, interpretado desde antiguo como el oecus de la villa, tiene mayores dimensiones que los demás, ya que alcanza los $95 \mathrm{~m}^{2}$ y ocupa casi todo el espacio construido sobre ese lado del patio-peristilo. El suelo de este ambiente, con estrado en la cabecera, estuvo solado con un bello mosaico policromo de fino diseño y compleja composición, aparecido en excavaciones del año 1942 en bastante buen estado de conservación. Fue cubierto en 1973 de modo inadecuado y, a lo largo del tiempo transcurrido desde entonces, ha resultado destruido en un $70 \%$ de su superficie total conservada (Hernández, 2000,441 ), hasta el punto de que para apreciar el diseño hay que recurrir a las fotografías anteriores a la consolidación de los años 70 (Mañanes, 1992, Láms.VI y VII.- Neira y Mañanes, 1997, 119-121, Lám. 26 ). Tiene un emblema poco usual: un espacio cuadrado orlado por la consabida guirnalda de hojas con discos en los ángulos y los puntos medios de cada lado, donde se inscribe un gran disco que contiene entre dos diademas de orfebrería con gemas, una vistosa guirnalda foliácea con broche central, rodeando una rosácea.

\section{El sector meridional}

Es la zona de la casa, la mejor conservada, donde las recientes excavaciones han ampliado más la planta. Aquí las paredes conservan mayor altura

${ }^{10}$ Este mosaico fue restaurado deficientemente en fecha imprecisa en los setenta, con soporte de vinilo que forzó su estallido y deterioro agravado por la intemperie. En 1992 fue protegido con malla geotextil y tierra y en 2001 ha sido definitivamente restaurado. 

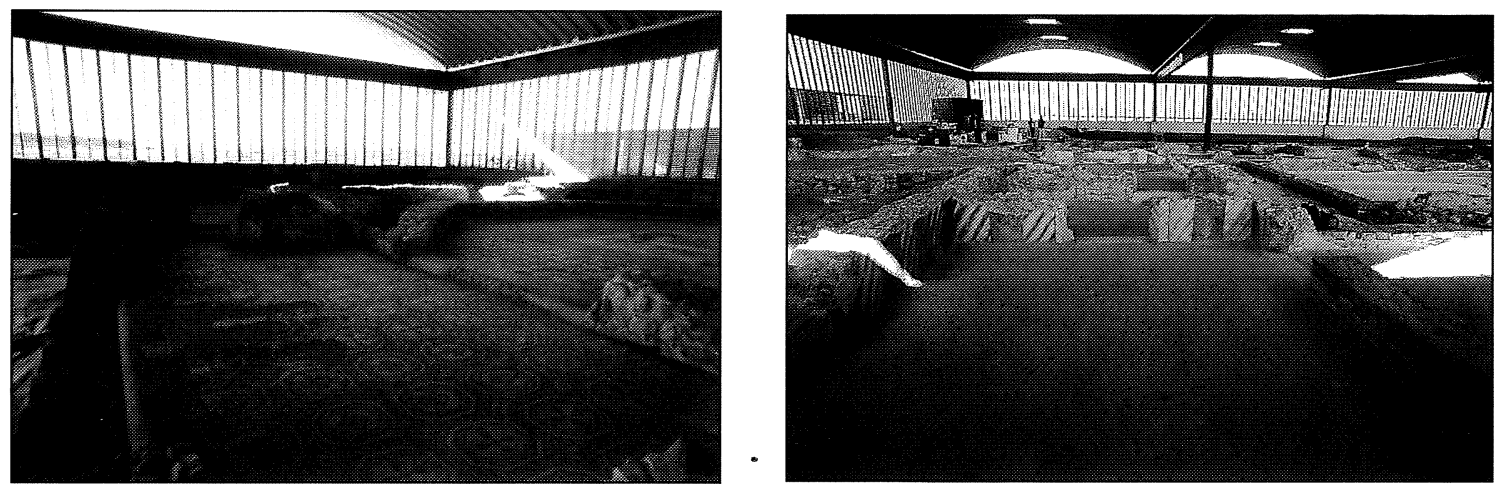

Lám. I. 1. Villa de Almenara de Adaja (Valladolid). Antecámara del oecus octogonal (Fotografía de C. García Merino).- 2. Villa de Almenara de Adaja (Valladolid). Habitaciones de la zona sur, comunicadas con el salón octogonal con tema de Pegaso. Obsérvense los restos de los revestimientos parietales (Fotografía de C. García Merino).

por lo que se han preservado parte de los zócalos de las pinturas murales. El gran peristilo ajardinado del sur $\left(258 \mathrm{~m}^{2}\right)$ (fig. $\left.1, \mathrm{n}^{\circ} 19\right)$ articula todo el sector, mucho más compartimentado pero también más amplio que el del norte donde, combinada con las actividades de representación y recepción, se desarrollaría la vida (no la vida privada), del dominus y su familia. Las habitaciones tienen dimensiones más reducidas que en el otro peristilo, a excepción de dos grandes salones que se sitúan en posición relativa ortogonal.

El oecus octogonal. Uno de esos salones (fig. 1, $\mathrm{n}^{\circ} 34$ ), en el extremo del eje mayor del edificio, opuesto al oecus del norte, es de planta poligonal con una superficie de $55 \mathrm{~m}^{2}$ y está precedido por una antecámara de $22 \mathrm{~m}^{2}$ (Lám. I,1). Tiene un pavimento musivo figurado con tema mitológico, indicador de la importancia de este espacio y su posición en la jerarquía social, conforme al código del lenguaje simbólico.

El mosaico. El emblema está centrado en un tapiz de peltas negras con remate rojo sobre fondo blanco. El efecto es bellísimo por destacar más aún sobre el claro y sencillo entorno del tapiz la escena figurada que sobre un fondo blanco de teselas dispuestas en abanico; representa a Pegaso entre dos ninfas y la personificación de la fuente Hipocrene, relacionada también con el relato mitológico del sobrenatural équido. (Lám. II).

La escena de Pegaso, sorprendentemente áptero, se ha tratado ya sobradamente, en particular por F. Regueras y E. Pérez Olmedo que recogen toda la bibliografía anterior (Mañanes 1992, 68-71; Neira y Mañanes, 1998, 30-34; Regueras y Pérez, 1998, 2840). Queremos, sin embargo, subrayar la originalidad de la representación que combina la escena, poco usual y con paralelos africanos, del cuidado de Pegaso por las ninfas que lo lavan en un curso de agua, lo cepillan y adornan con guirnaldas, con la de una fuente, en este caso Hipocrene, nacida de un golpe del casco de Pegaso. En Hispania aparece en sólo otros dos mosaicos: en San Julián de la Valmuza (Salamanca) y en Écija y posiblemente en un tercero de Arróniz (Regueras y Pérez, 1998). La fuente Hipocrene, cuyo nombre alude precisamente a su origen, se ha efigiado como una figura femenina con vaso manante, recostada en un fondo paisajístico abstracto que evoca el monte Helicón (Lám II).

La escena de Pegaso y las dos ninfas se ha querido ver como alegoría de las actividades intelectuales (ninfas-Musas), Pegaso metáfora de los impulsos humanos dominados por la mente, y el autocontrol, símbolo de la libertad, de la capacidad creativa o, incluso, como alegoría del matrimonio (Regueras y Pérez, 1998, 37). En nuestra opinión puede entenderse también en este caso, por la asociación de esas dos escenas, como referencia al nacimiento mítico de las aguas a través de la figura de Pegaso, causante de la eclosión de una fuente y cuyo propio nombre deriva de uno de los términos griegos que significan manantial.

La anómala ausencia de alas en la figura de Pegaso, sin duda intencionada pues un error de los musivarios se hubiera corregido, podría interpretarse también en relación con el deseo de mostrar un caballo concreto, terrenal, es decir de mostrar en el papel de Pegaso al caballo favorito del dominus. Realmente nunca sabremos las razones por las que Pegaso no es alado pero la bella cabeza del équido representado con una mancha blanca en la frente, parece el «retrato» de un animal concreto (Lám. III,2). En Aguilafuente, a pocos km. al este de Almenara, el tema de los caballos es recurrente (Lucas 


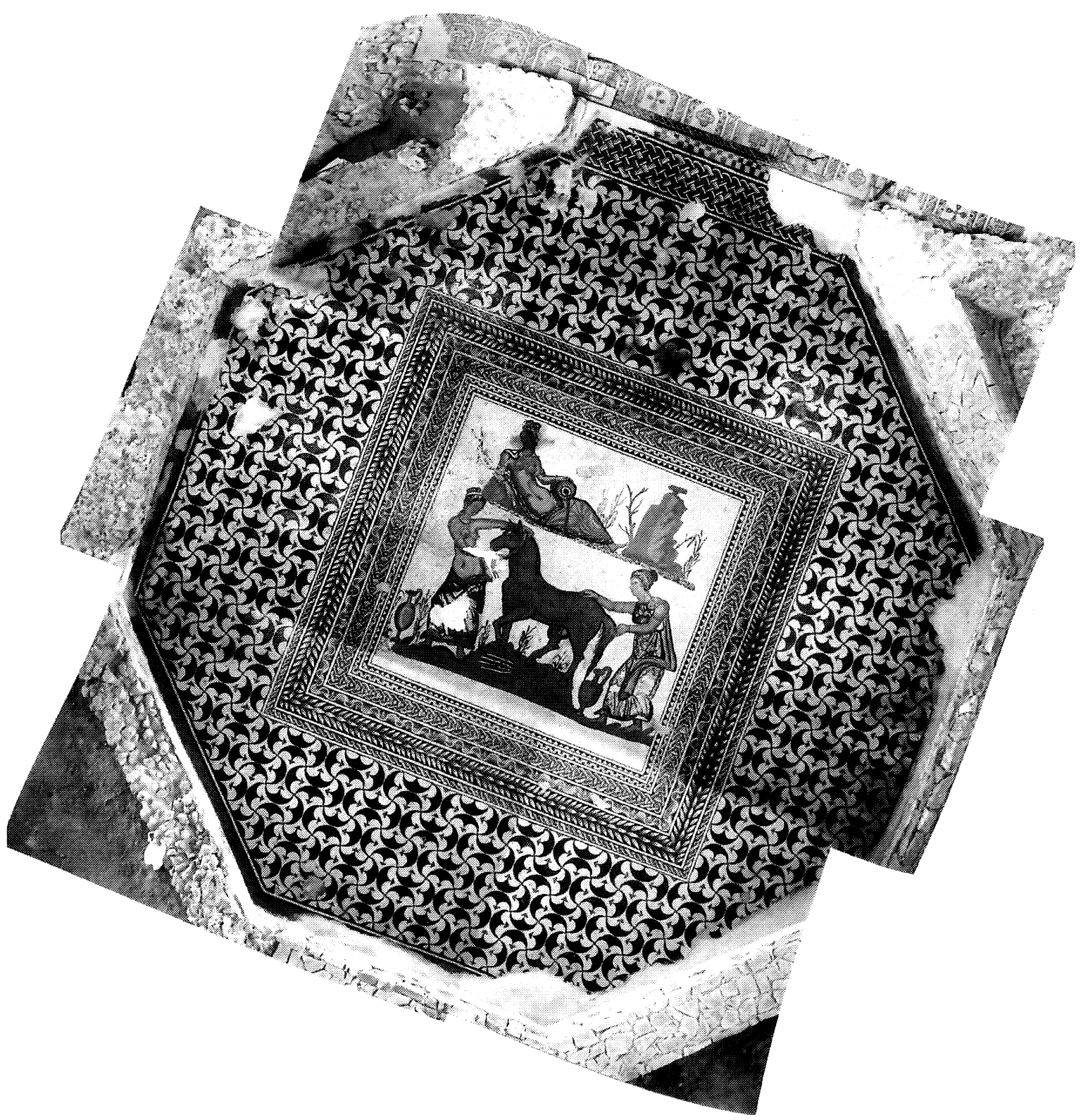

Lám. II. Villa de Almenara de Adaja (Valladolid). Mosaico del oecus octogonal. Vista de conjunto. (Ortofotografía de G. Gillani).

y Viñas, 1977, 245 y Lám.VI.; Lucas, 1987, 221227) con representaciones que según $M^{a} R$. Lucas se encuadran en las escenas de équidos ganadores de carreras de carros del circo, con claros paralelos en la iconografía africana (Lucas, 1987, 228-235). No cabe duda de que en el mundo de las villas los caballos no sólo eran imprescindibles para viajar, sino que, como ilustran algunas representaciones musivas y pictóricas, la pequeña plástica y la literatura, el caballo estaba presente en las principales activi- dades lúdicas y deportivas, que eran la caza y las carreras del circo. Los propietarios tendrían siempre una cuidada cuadra. El mismo sentido podría tener la representación del caballo de las termas de la villa de Dueñas, espléndida imagen concretada con la leyenda Amoris. Tal vez el dueño de la villa de Almenara quisiera retratar a su caballo favorito en una representación mítica como era de rigor para un salón noble, en este caso celebrando el agua, con Pegaso y la fuente. 

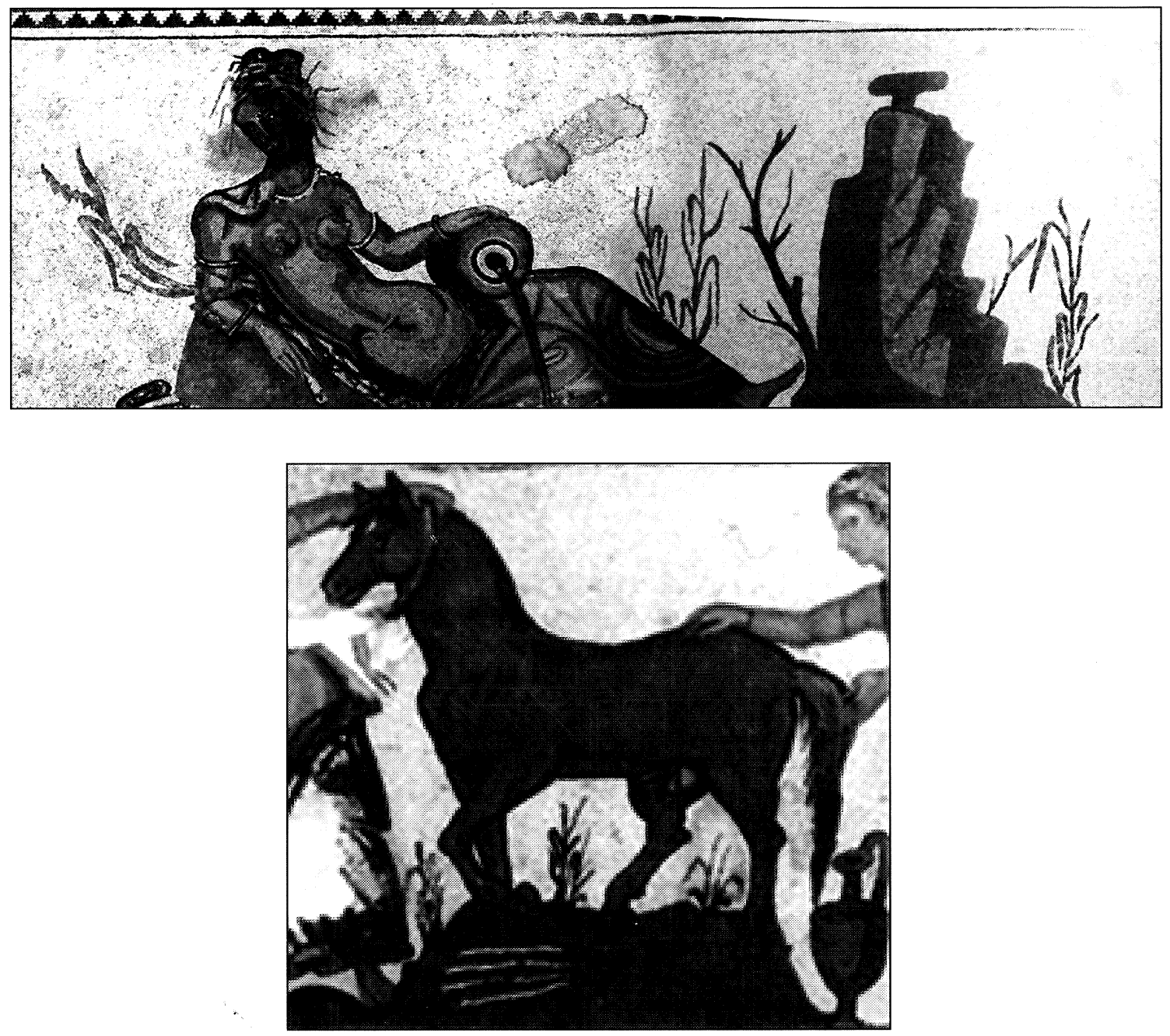

Lám. III. 1. Villa de Almenara de Adaja (Valladolid). Mosaico del oecus octogonal. Detalle del registro superior del emblema. La fuente Hipocrene. (Fotografía de G. Gillani).- 2. Detalle con Pegaso áptero (Fotografía de G. Gillani).

Es interesante el hecho de que la escena esté orientada de modo que la vista óptima de ella se obtiene desde el fondo de la habitación, mirando hacia el norte, lo que parece abonar la idea de la instalación ahí de asientos o lechos en semicírculo. Esa orientación, infrecuente, en los contados casos en que ocurre no tendría, según Dunbabin, un significado especial, solo responde a lograr el mejor punto de vista (Dunbabin, 199, 315-316). Este salón, lo mismo que el triclinio o cenatio absidado del patio norte (fig. $1, n^{\circ} 3$ ), se comunica con unas habitaciones que forman una suite abierta a la antecámara, en la parte menos deteriorada de la casa, donde las paredes conservan casi un metro de su altura original. Está formado por una pequeña antesala ( $\left.n^{\circ} 32\right)$ accesible también desde el jardín porti- cado y dos habitaciones, una de ellas ( $\left.\mathrm{n}^{\circ} 31\right)$ quizá sala o triclinio, y la otra $\left(\mathrm{n}^{\circ} 30\right)$, dormitorio.

Es indudable el carácter especial de esta exedra no sólo por la decoración sino también por su situación, en un extremo del eje longitudinal de la residencia y abierto al peristilo sur, por lo que disponía de una hermosa perspectiva desde el jardín hasta el oecus de cabecera poligonal del otro extremo del eje. Además, la posición en el fondo de la casa, en un extremo del peristilo, la zona menos accesible, como culminación de una secuencia de espacios intermedios y en un nivel más alto que la antecámara, subraya su importancia. Este oecus estaba planificado para lograr lo que se ha definido como máximo impacto en el punto de máxima efectividad (Wallace-Hadrill, 1988, 48). 
Salón de planta ultrasemicircular. El otro salón, en el extremo oriental del eje menor del peristilo (fig. 1, $\mathrm{n}^{\circ} 29$ ), con $75 \mathrm{~m}^{2}$ de superficie, es de planta ultrasemicircular en cuyo contorno se esbozan tres lóbulos, perfectamente marcados en la decoración musiva del pavimento. El acceso se hace por el vano más grande de la casa, con dos soportes en el centro, realmente un triple vano. Se descubrió en 1942 y entonces aún conservaba las basas de las columnas y parte del zócalo de las pinturas murales (Nieto, 1942-43, Láms. III y IV). Orientada al oeste, esta sala pudo servir entre otros usos, como un agradable triclinio de verano abierto al jardín. El mosaico presenta un gran emblema cuadrado que incluye teselas vítreas. Está enmarcado por una serie de molduras, la más externa de las cuales es una guirnalda de hojas jalonada por broches circulares como gemas, según hemos visto en otros puntos de la casa. La destrucción del pavimento en todo el centro de la estancia, es casi completa ${ }^{11}$ como se podía apreciar ya en fotografías anteriores (Mañanes, 1992, Lám. XIII). También han desaparecido la decoración del umbral y las basas. Se percibe la presencia de elementos vegetales y cráteras en los ángulos del espacio donde se inscribe el motivo central. Es interesante señalar que el motivo que forma el tapiz de los lóbulos - un cuadrado segmentado con efecto arco iris- evidencia peor factura en el lóbulo septentrional donde ofrece irregularidades, tanto en las líneas como en el empleo de las tonalidades, indicios de haber sido reparado o hecho por otra mano.

El resto de las dependencias son grupos de dos o tres piezas intercomunicadas que forman pequeños apartamentos - diaetae o zothecae - constituidos por una sala y un dormitorio, o por una antecámara, una sala o triclinio (triclinio matronarum?) y un cubículo o por antecámara y sala de estar. Son cinco grupos: (fig. $1, \mathrm{n}^{\text {os }} 23$ y $22 ; \mathrm{n}^{\text {os }} 21$ y $20 ; \mathrm{n}^{\text {os }} 38,37$ y $36 ; n^{\text {os }} 32,31$ y 30 y $n^{\text {os }} 26$ y 27). El clima frío durante la mayor parte del año fue sin duda lo que determinó que el acceso a esos aposentos no se hiciera directamente desde el peristilo sino a través de una antecámara. De ahí que sea en esta parte de la casa donde se encuentre la única pieza (fig. $1, \mathrm{n}^{\circ} 20$ ) con calefacción por sistema mixto de canales de aire e hipocausto, muy poco frecuente en Hispania ${ }^{12}$ y que esté flanqueada por dos cubicula $\mathrm{n}^{\text {os }} 37$ y 22 (Lám. IV, 1).

Los muros tienen la parte baja de caementicium

\footnotetext{
${ }^{11}$ Fue exhumado en 1942 o 43 por G. Nieto. Después fue arrancado y trasladado a Medina del Campo de donde se ha recuperado y reinstalado en 2001.

${ }_{12}$ En Ronchinne (Francia) hay un caso similar pero con seis pilae en lugar de cuatro (Degbomont, 1984, 129).
}

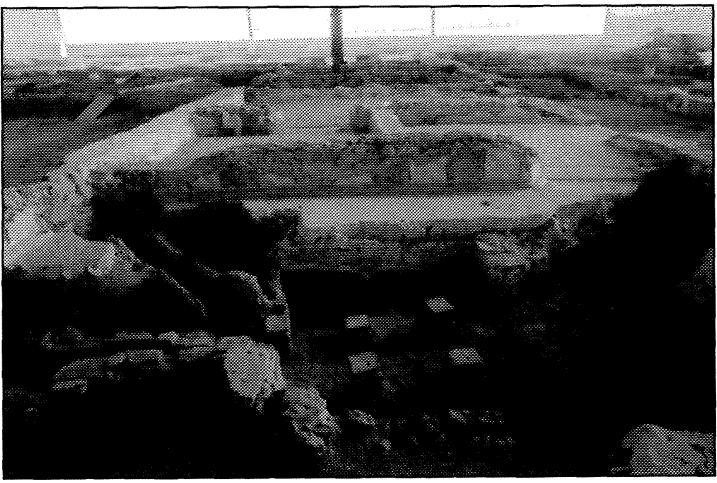

Lám. IV. 1. Villa de Almenara de Adaja (Valladolid). Zona sur de la pars urbana. En primer término el hipocausto de la habitación 20. (Fotografía de C. García Merino).

de caliza y mortero, el alzado sería seguramente de tapial. Estaban revestidos de mortero con pinturas al fresco. Lo conservado corresponde al zócalo consistente en todos los casos en la simulación de placas marmóreas de pórfido rojo y mármol blanco o veteado donde se combinan los colores rojos, negro, blanco y crema (Lám. I, 2). Nada se puede decir por el expolio del resto del alzado y del techo, a excepción del oecus con mosaico de Pegaso donde se hallaron varios fragmentos, uno de ellos con la cabeza de un felino en un medallón, pues aunque se han recogido numerosas placas de revestimiento parietal, están aún sin estudiar. De las antiguas excavaciones hechas en ciertos puntos, se conservan también porciones de pinturas murales descontextualizadas, pendientes aún de estudio.

Es de notar que en la mayoría de las habitaciones menores los vanos ocupan solo la mitad del ancho del muro; en la otra mitad el hueco de la puerta se abre en bocina hacia el interior. En los salones los accesos son mucho más amplios y tienen umbrales de una sola pieza, a veces de mármol. En cuanto a los suelos, el de las galerías del peristilo era de mortero blanco, conservado solo en pequeñas manchas y en las habitaciones cuando no es de mosaico, es de signinum sobre una sólida base, con pulida superficie de tono rosado y una moldura de cuarto de círculo en el contacto con la pared.

Completa la zona un amplio espacio al exterior (fig. $1, \mathrm{n}^{\circ} 50$ ), cercado por una ancha tapia de piedra que era seguramente una zona de servicio entre las cellae (fig. 1, A) y las termas.

\section{El balneum}

Las recientes excavaciones realizadas dentro del proyecto de recuperación integral han documentado 
una serie de cambios en la planta que revelan la evolución estructural del balneum desde el inicio de su construcción. Hechos como la modificación de algunos accesos, la colocación de un mosaico sobre un pavimento anterior de opus signinum, la prolongación del pasillo hacia el norte y la adición de más espacios construidos que suponen no solo la ampliación, sino también la monumentalización del balneum, apuntan, sin duda, en esa dirección. Así esta parte de la casa se muestra como un espacio de representación, relacionado con las prácticas sociales.

Aunque buena parte de estas instalaciones fue descubierta por G. Nieto en 1942 e interpretada cuarenta años después por A. Balil $(1994,42)$ como el área termal de la villa, apenas existía información sobre ellas. Han sido descritas recientemente por V. García Entero, basándose en las escasas referencias publicadas, como un conjunto de aproximadamente $182 \mathrm{~m}^{2}$, compuesto por tres elementos: frigidario con piscina, tepidario ampliado en cierto momento, y con alveus calentado por un hipocausto exclusivo y caldario sobre otra cámara de calor (García Entero, 2001, 266-268).

Una vez terminada la excavación de este sector, se observa que los baños ocupan $387 \mathrm{~m}^{2}$, una superficie relativamente amplia, pero esas dimensiones responden a la última etapa de la vida de la casa.

Primera fase (fig.3). En un principio el balneum constaba de tres elementos: apoditerio-frigidario, tepidario y caldario (fig. $3,1^{\text {a }}$ fase). Había una sala (fig. $1, \mathrm{n}^{\circ} 40$ ) de $34 \mathrm{~m}^{2}$ con pavimento de signinum y pequeño pocillo circular como en algunos mosaicos, que pudo hacer de vestuario, e incluso de zona fría y, de ser correcta la identificación, en esta pieza se iniciaría conforme a los cánones, la secuencia lineal del recorrido del balneum. A continuación seguía un tepidario (fig. $1, \mathrm{n}^{\circ} 43$ ) de $27 \mathrm{~m}^{2}$, con suelo de signinum y una pequeña piscina con pavimento musivo que representa peces y delfines (Neira y Mañanes, 1998, 25, Lám. 29). El desagüe, bien conservado, se hacía por tubería de plomo, cuyo contorno se marca en el diseño del fondo de mosaico. Y, finalmente, un caldario de $25 \mathrm{~m}^{2}$ (fig. $1, \mathrm{n}^{\circ} 44$ ) con una gran bañera, colocada sobre la entrada de calor desde el praefurnio, ocupando casi la mitad de la estancia. La estructura del alveus ha desaparecido, lo mismo que toda la suspensura pero se conserva bien el desagüe en la pared occidental del caldario, así como 17 pilae del hipocausto y parte de la chimenea cuadrada de latericio, alojada en el ángulo nordeste de la cámara. En el centro del caldario, sobre el área del hipocausto, se aprecia parte de tres pilares de pedales de apoyo para la suspensura y para la gran bañera instalada sobre ella. El horno, situado al sur, corresponde al tipo IV de Degbomont, con canal de calor interior, y se encuentra en un espacioso propnigeum, $\left(23 \mathrm{~m}^{2}\right)$ accesible desde el exterior de la casa. La configuración del horno permitía calentar sobre su cubierta la caldera que alimentaba el baño. Este propnigeum, que enlaza con el área termal de la villa anterior, experimentó también una modificación cuando se tapió la puerta, situada en la pared oriental y se corrigió el muro del sur donde se abrió otro vano (fig. 3).

Completan el conjunto del balneum los restos de un pequeño espacio rectangular (fig. $1, n^{\circ} 49$ ) adosado al muro sur de la piscina del frigidario, que alberga en su interior una canalización practicada en el duro terreno natural. Hay también restos de otra atarjea transversal a la anterior bajo un boquete de desagüe, practicado a ras del suelo en la esquina sudoeste del frigidario. A pesar del arrasamiento que presenta, posiblemente haya que interpretar esta estructura como una letrina aneja a las instalaciones de los baños ${ }^{13}$.

Segunda fase. Modificaciones en el area balnear (fig. 3, 2 a y 2 b).

1) En los recientes trabajos de consolidación del mosaico del tepidario, se ha visto que bajo él hay un pavimento de signinum, es decir que, ya en uso los baños, se decoró este ambiente superponiendo al signinum un pavimento musivo de tema geométrico (Neira-Mañanes, 1988, 24, Láms 9 y 29).

2) Después se prolongó el pasillo y se construyó un frigidario rectangular de grandes dimensiones $-75 \mathrm{~m}^{2}$ - con suelo de signinum y una piscina de $2,3 \times 3 \mathrm{~m}$. centrada en su lado occidental. Contaba con tres puertas, una que lo unía al tepidario, otra en el ángulo noroeste, un posticum, que daba al exterior del edificio y la de acceso desde el pasillo, con un vano de $3 \mathrm{~m}$ de anchura. El suelo presenta unos huecos de forma circular, practicados en el pavimento, agrupados y distribuidos en tres grupos de cuatro. La interpretación de esas perforaciones no es fácil porque no hay paralelos, al menos publicados, pero es clara su intencionalidad. Menos evidente es su función. Pensamos que podrían estar en relación con el anclaje de elementos del mobiliario. Por ejemplo lechos para masajes, etc ${ }^{14}$. Perforaciones semejantes

\footnotetext{
${ }^{13}$ Esta disposición de la letrina al exterior del frigidario y a un costado de la piscina, recuerda la de la correspondiente del segundo balneum de Centcelles (García Entero, 2001, 240).

${ }^{14} \mathrm{Su}$ disposición concuerda con la situación de tres lechos en un lado y un banco corrido en otro. Los lechos para masajes, unciones, etc. no deben moverse y sus patas, encajadas en el pavimento, proporcionarían la estabilidad y fijeza requeridas para el tratamiento corporal de los bañistas.
} 

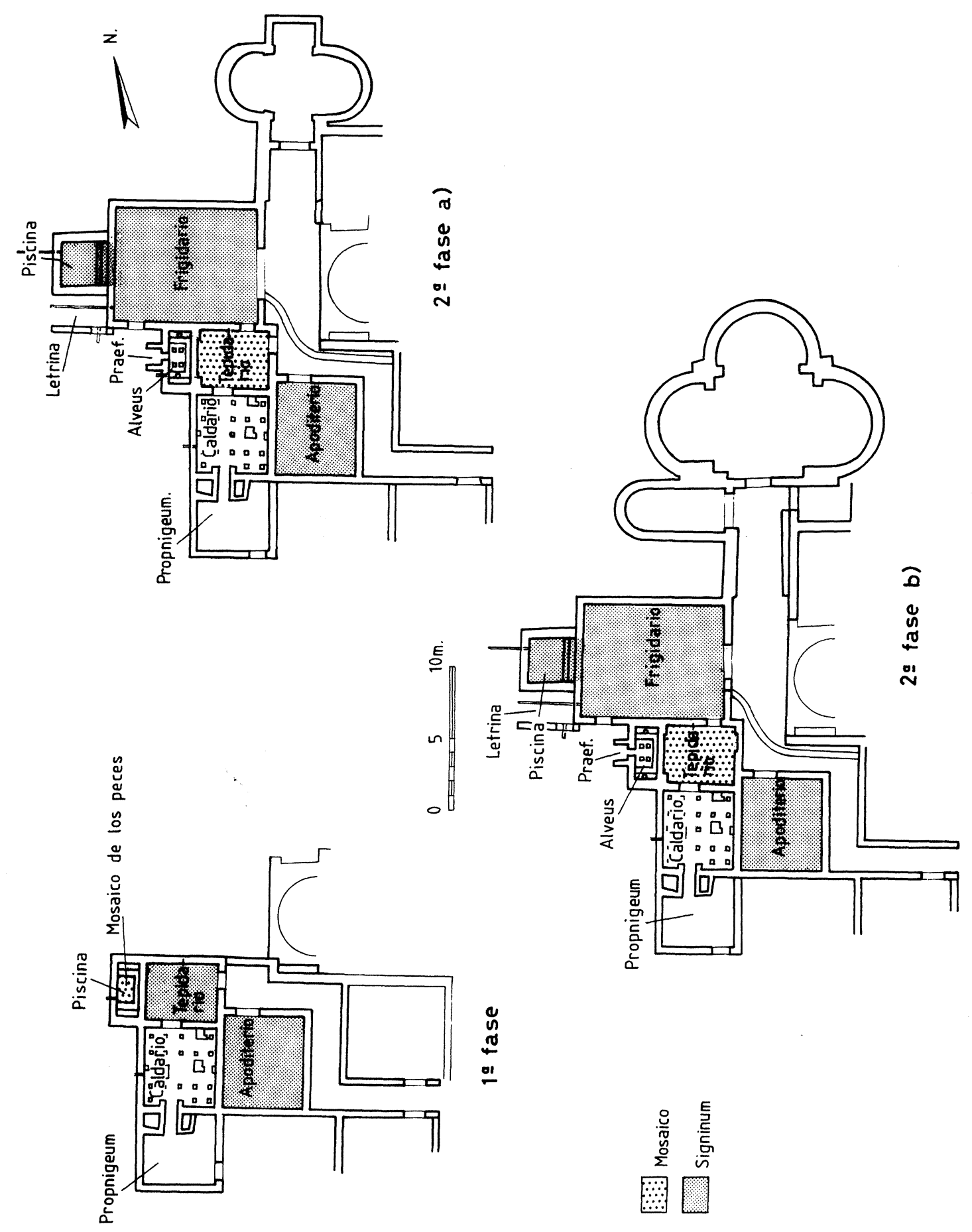
pero de forma triangular con un lado algo curvo, perfil trapezoidal y hechas a la vez que el opus signinum, presentan también los pavimentos de dos habitaciones de los apartamentos del sur, la $\mathrm{n}^{\mathrm{o}} 30 \mathrm{y}$ la $\mathrm{n}^{\circ} 32$ de la figura $1^{15}$.

3) La dotación de un nuevo frigidario conllevó un importante cambio en el tepidario: una bañera de agua caliente sustituyó al baño frío para lo cual la piscinita de los peces se convirtió en solera de un pequeño hipocausto con su propio horno (tipo III de Degbomont) y dos chimeneas tubulares de cerámica embutidas en los muros laterales.

4) La puerta que comunicaba hasta entonces el tepidario con el pasillo fue cegada en su parte externa, respetando el umbral del mosaico y la moldura de cuarto de círculo de las jambas.

Con las reformas, la estancia 40, vestuario y vieja zona de masajes, etc. quedaría solo como apoditerio y desde ella se iniciaría la circulación por los baños conforme al esquema lineal retrógrado: frigidario-tepidario-caldario y, de vuelta: caldario-tepidario-frigidario-apoditerio.

5) La gran sala triconque (fig. 3, fase 2 b).

Más adelante, la puerta principal del frigidario se estrechó, el pasillo se prolongó más aún y se le añadió como zona fría un gran espacio $-127 \mathrm{~m}^{2}-$ con un salón de compleja planta (fig. $1, \mathrm{n}^{\circ} 48$ ), precedido de una antecámara y con una sala rectangular absidada (fig. $1, \mathrm{n}^{\circ} 46$ ) con un vano en la cimentación de la cabecera para drenar la humedad permanente del terreno a causa de la proximidad a la superficie del nivel freático. Estas estructuras que se descubrieron parcialmente en los años 80 , fueron interpretadas por Balil como las trazas de un mausoleo que no llegó a levantarse (Balil, 1994 (1989), 82). Las excavaciones de finales de los años 80 y comienzos de los 90 , orientadas a la delimitación de la villa y centradas básicamente en la zona sur, nada nuevo aportaron acerca de ellas, por lo cual el plano de la villa conocido hasta ahora, presenta esta parte de la planta de manera fragmentaria. Mañanes dice que el pasillo termina en «el gran edificio tríjoro» que en la puerta está «precedido por dos cuartos de esfera que servirían como contrafuerte» (Mañanes 1992, 46) y aunque menciona paralelos a la planta, elude ante la falta de datos, una interpretación concreta de su funcionalidad. Mas tarde Regueras y Pérez Olmedo, al hilo del estudio de los mosaicos de la villa salman-

${ }^{15}$ Sus dimensiones son $14 \mathrm{~cm}$ de longitud, 7 de anchura máxima y 10 de profundidad. En la sala $n^{\circ} 30$ son tres, distribuidos a lo largo de la pared norte, a $29 \mathrm{~cm}$ de distancia del rodapié. Dos de ellos alineados y separados entre sí por una distancia de $1,98 \mathrm{~m}$. En la pieza $\mathrm{n}^{\circ} 32$ son dos, a un lado de la puerta que comunica con la antecámara 39. tina de San Julián de la Valmuza, hacen un estudio detenido de la planta con sus paralelos (Regueras y Pérez Olmedo, 1997, pp. 20-28) y, después, Regueras a propósito de la villa de los Casares en Armuña (Segovia), descubierta a través de la fotografía aérea, analiza esas estructuras y su posible significado como triclinio ceremonial, aludiendo a su carga semántica, asociada siempre a las elites más poderosas del Imperio (Regueras y del Olmo, 1997, 678). Señala este autor la concentración de ejemplos de esa planta en el entorno de Cauca y revisa la cuestión de su debatida relación con las propiedades del clan teodosiano en Hispania. La inclusión de Almenara entre los ejemplos citados sugiere que la considera como aula ceremonial. Sin embargo, como el propio Regueras reconoce, la traza tríconque se encuentra, tanto en construcciones termales como en construcciones de carácter funerario o religioso.

La interpretación de esta compleja parte del edificio, sin duda levantada con posterioridad al ascenso al poder de Constantino y más tarde que el resto del edificio, resulta problemática. En 2001 se ha reexcavado la parte conocida y completado la exhumación de la cámara trilobulada, descubriendo que parcialmente inserta en ella hay otra de planta cruciforme biabsidada (fig. 3, fase $2 .^{\text {a }}$ a) ${ }^{16}$. La desnudez de las estructuras de opus caementicium, la falta de datos de excavaciones anteriores y las huellas de expolio de elementos constructivos y ornamentales con que ha llegado a nosotros (aunque se ha profundizado hasta la tierra virgen en las zonas aún intactas, los únicos materiales documentados en el nivel de destrucción son tejas de la cubierta y algunos bloques de ladrillo y mortero de las bóvedas) dificultan extraordinariamente el análisis de esa extraña asociación.

Dos problemas se plantean a la hora de comprender estas estructuras: uno el propio trazado y el otro, la función que desempeñaron. Respecto a lo primero, se puede observar que la traza de los muros ofrece el aspecto de dos plantas distintas (fig. $1, \mathrm{n}^{\text {os }} 46$ y 47) que en Almenara no se dan en diferentes puntos de la casa, sino imbricadas hecho notable ya en si mismo. Hay una planta cruciforme biabsidada y otra trilobulada (realmente planta cuadrada con ábsides en tres de sus lados), que iría cubierta por cúpula central con tres hemicúpulas. En alzado, la contemporaneidad de ambas plantas es imposible. La dualidad, en principio, solo se justificaría si una hubiera sustituido a la otra y se hubiera apoyado en sus fundamentos. Aunque sólo en algunos puntos de la

${ }^{16}$ Se ha hallado también el cimiento de piedra de un muro, orientado en sentido este-oeste, correspondiente a la villa anterior, donde apoyan los ábsides y la cabecera de la planta cruciforme. 
traza es evidente la superposición de los ábsides de la trebolada sobre los muros de la cruciforme, es lógico deducir que se sucedieron en el tiempo. Primero se planteó la cruciforme (fig. 3 , fase $2^{\mathrm{a}}$ a) y después - no hay datos para precisar cuándo- se levantaría la triabsidada sobre los cimientos de la otra que le servirían como apoyo y arcos de descarga de la cubierta ${ }^{17}$.

El segundo problema es averiguar el uso dado a la sala triconque y sus anejos. Este tipo de planta que se da en edificios de diferente carácter y función, lo encontramos aquí en la parte de la casa dedicada a los baños y conectada con ella por un pasillo que sale del peristilo sur. Las evidentes reformas realizadas en el área de los baños para ampliar su superficie nos llevan a considerar como lo más probable que este espacio triconque y la cámara asociada, tuviesen el carácter de zona fría aneja a los baños. En las villas de Aquitania, en la última fase bajoimperial, es casi general que las zonas frías de las termas estén muy desarrolladas (Balmelle, 2001, 178 y ss). Asimismo, en las villas hispanas cuya cronología se conoce bien, las salas termales con plantas dotadas de ábsides en sus distintas modalidades, son de construcción tardía (finales del siglo IV, incluso del siglo v) y, a veces, fruto de añadidos a los baños preexistentes, como ocurre en Navatejera (León) donde la residencia señorial se reformó en la segunda mitad del siglo IV o ya en el V, pavimentando con mosaico algunas estancias de las termas y añadiéndoles dos grandes espacios pues, a pesar de las dificultades existentes para su interpretación, estas dependencias parecen estar relacionadas con las termas (García Entero, 2001, 153-155).

Por todo ello cabe pensar que los balnea eran un recurso para mostrar el confort, el nivel económico $y$, en definitiva, el rango del dueño. Probablemente por ello se añadieron esas grandes salas, en otros casos aulas ceremoniales o mausoleos, utilizadas en los ambientes termales como áreas de recreo complementarias de los baños e, incluso, como oeci o cenationes ocasionales.

\section{Otras dependencias y servicios de la vivienda}

El abastecimiento de agua se hacía desde el viejo pozo (fig. 1, B) que ya servía a las termas preexistentes. Con este pozo de 3,50 m de diámetro,

${ }^{17}$ Así parece lógico descartar que se construyeran a la vez, con lo que la cruciforme no sería tal, sino refuerzo de cimentación de la otra a causa del declive del terreno en esta zona y también la posibilidad de un cambio de traza de la nueva construcción en el planteamiento de la subestructura, buscando quizá mayor espacio y mas suntuosidad. dada además la escasa profundidad del nivel freático en esta zona, y la abundancia de charcas y labajos, la disponibilidad de agua estaba garantizada.

Como suele ocurrir en general en las casas de época romana, tampoco en la villa de Almenara hemos hallado evidencias de la cocina. Para identificar el área servil y por tanto la cocina y despensas, el sector más idóneo parece estar en la esquina nordeste (fig. $1, \mathrm{n}^{\text {os }} 10$ a 15 ). Sin embargo, hay que tener en cuenta que la disponibilidad de braseros portátiles, facilitaba el transporte de comida a las salas destinadas a comer desde áreas alejadas y el utilizar brasas podía permitir guisar en habitaciones sin una fisonomía específica. De los $\mathrm{n}^{\text {os }} 14$ y 15 —éste con suelo de baldosas y blanco corrido- arranca el ala norte de la pars rustica.

\section{Los paralelos}

En cuanto a la arquitectura, en la disposición de la planta el paralelo es la villa de Los Quintanares en Rioseco (Soria) (Ortego, 1977) porque distribuye las habitaciones en torno a dos patios porticados. También la de Santervás del Burgo (Soria) se asemeja por disponer de una sala circular y otra cruciforme bilobulada que podrían haber formado parte de unas termas como laconicum y tepidarium respectivamente (García Entero, 2001, 220). Pero donde, lógicamente, hallamos más semejanzas constructivas es en el entorno de Cauca, en la villa de Santa Lucía de Aguilafuente (Segovia). Los paralelos se observan en el aparejo de los muros, en el tipo de desagües, en las atarjeas y canales de aire realizados con ladrillo (Lucas y Viñas, 1977, figs. 2 y 3 Lám. II) en el tipo de pavimento de mortero, en el empleo exclusivamente de teja curva en las cubiertas, en la presencia de una sala de recepción con cabecera poligonal. Además, en el área de los baños de esta villa se emplea la planta cruciforme trilobulada -en este caso con canales de calor- pero también hay una gran sala rectangular, $\mathrm{n}^{\circ} 27$, donde no se ha documentado hipocausto y que parece un ambiente frío. Finalmente otra nota común es la presencia de muros de cantos rodados y lechadas de yeso en niveles superpuestos a las ruinas de la pars urbana, tal vez de época tardorromana o visigoda (Lucas y Viñas, 1977, 252).

\section{LOS MOSAICOS}

Al día de hoy el conjunto de mosaicos de Almenara, uno de los más vistosos y ricos de las villas de la meseta, consta de dieciocho pavimentos de los 
cuales solo dos son figurados, proporción que en general no tiene nada de raro en estos territorios del centro peninsular. Han sido publicados ya en dos ocasiones (Mañanes, 1992, 55-71; Neira y Mañanes 1998, pp.13-34) por lo que nos limitaremos a realizar solamente unos comentarios, considerándolos globalmente e incorporando algunos datos obtenidos en las intervenciones llevadas a cabo entre 1998 y 2002.

En los trabajos de consolidación y restauración efectuados en 2000 y 2001, se ha comprobado el empleo de una misma técnica que, unida a la presencia reiterada de ciertos elementos decorativos y determinados rasgos de ejecución, muestran que todos los mosaicos, salvo el del tepidario, se hicieron en la misma época, dentro de un programa y en algunos casos por el mismo grupo de artesanos. Es perceptible la unidad temática de los pavimentos de los lados norte y oeste del patio 2, es decir los del salón 7 , el triclinio 3 y el pequeño recibidor 5 . Los tres presentan motivos similares, si bien en composiciones muy diferentes. Esa temática es aquí un código que indica que esas habitaciones ocupan el mismo destacado puesto en la jerarquía de espacios sociales. Tales elementos enlazan, como ya vio Torres, estos mosaicos de Almenara con los de la villa de Prado, también en Valladolid, obra de un mismo taller caracterizado por un tipo de guirnalda (Torres, 1990, 229). Hay por otra parte, una serie de motivos que se repiten en los mosaicos de Almenara y los interrelacionan; se trata de cráteras de las que salen largas hojas de bordes dentados, cuatripétalas blancas de contornos redondeados y pequeñas bolas blancas, a modo de capullos diseminados sobre fondo oscuro. También son grandes guirnaldas circulares o coronas de hojas de laurel, los pequeños círculos radiados con efecto arco iris, situados en los ángulos de los enmarques cuadrados de las guirnaldas, y las cenefas de flores de loto bordeando los grandes paños del mosaico (Hasta que se publique un estudio global sobre la villa, se pueden ver las fotografías de estos motivos en Neira y Mañanes, 1998, Láms. 7, 26-28 y 4, respectivamente).

Se emplea piedra de diversos colores, cerámica y teselas de pasta vítrea verdes, azules y en algunos casos con pan de oro. Predominan los tonos cálidos, naranjas y rojizos unidos a los grises. Los sustratos son muy sólidos y cuidadosamente hechos, a excepción del tepidario, de peor calidad, y en algunos se observan reparaciones de época que no llegan a la altura de los originales, como las del salón 29. Las efectuadas sobre el suelo del tepidario son las más llamativas. También resulta curiosa la anomalía que presenta el pavimento de la sala $n^{\circ} 36$, en los apar- tamentos del sector meridional, con tapiz uniforme de círculos secantes (Neira y Mañanes, 1998, Lám. 10), hecho claramente en dos mitades a partir del centro. Cada mitad presenta diferente efecto cromático sobre el mismo motivo geométrico.

En los mosaicos que decoran las habitaciones nobles y de representación se combinan elementos vegetales y geométricos como tapiz con emblema central. En otros dos, n $^{\text {ss }} 5$ y 27 , de menor tamaño pero reconocibles también como salas asociadas a las de recepción ${ }^{18}$, no hay emblemas pero la composición del mosaico subraya la zona del fondo, algo más elevada. En estas estancias se encuentran los tonos azules y verdes conseguidos con teselas vítreas y es, si exceptuamos el mosaico de peces de la piscina del tepidario, donde se encuentra la única representación figurada. Merece mención también la presencia y buena conservación de los pocillos cuya finalidad generalmente se entiende que fue facilitar la limpieza del suelo. Estos pocillos con decoración propia, se hallan en los mosaicos de la aludida unidad temática, es decir en los de los grandes salones (posiblemente también comedores) 3 y 7 , y el más pequeño pero relacionado con ellos, 5 .

En las habitaciones de dimensiones moderadas, salas de estar, dormitorios, antecámaras, del sector meridional, el pavimento musivo es un tapiz uniforme de motivos geométricos donde lo vegetal solo aparece reducido a abstracciones de cuatripétalas, como en 36 y 38.

El nuevo mosaico. Se descubrió en la campaña de excavaciones de 2001. Tiene $8 \mathrm{~m}^{2}$ y decora uno de los cubículos meridionales (fig. $1, \mathrm{n}^{\circ} 22$ ), a un costado de la sala calefactada (fig. $1, \mathrm{n}^{\circ} 20$ ). Se accede a este dormitorio por la sala $\mathrm{n}^{\circ} 23$ cuyo suelo presenta un notable desgaste en la zona de tránsito. Las paredes se conservan en $60 \mathrm{~cm}$ de altura, mostrando parte del zócalo pintado al fresco donde se percibe alguna línea roja sobre fondo blanco sin que se pueda precisar más. La puerta ocupa solo parte del ancho del muro y las jambas se abren en bocina hacia el interior.

El mosaico (Lám. IV,2), sencillo pero bello pavimento que destaca por su extraordinaria conservación, es un tapiz uniforme formado por el motivo de escamas, bordeado por una cenefa de trenza de dos cabos. El colorido es blanco, beige y rojo. Se juega con el efecto cromático llamado de arco iris, a base de dividir en sentido vertical los semicírculos imbricados y rellenar cada mitad con diferentes colores,

${ }^{18}$ Tal vez pequeños comedores o salas con alcoba o dormitorios donde podía recibirse a los amigos. 


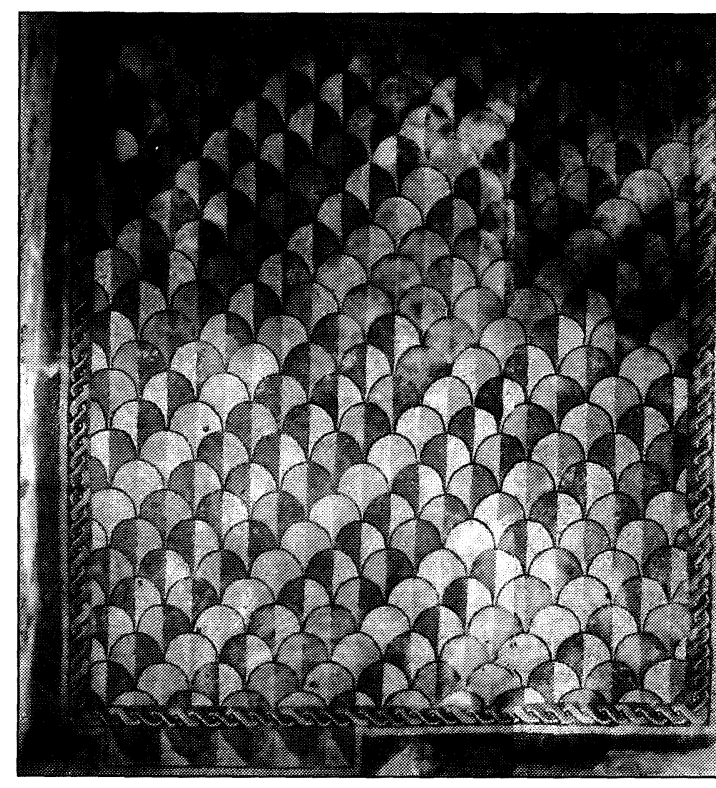

Lám. IV. 2. Mosaico hallado en 2001 en el cubículo 22 (Fotografía de G. Gillani).

gradando tonos. Encontramos paralelos a ese tema, por citar solo algún caso de la meseta, en Quintanilla de la Cueza (Palencia) (García Guinea, 1971, $190, n^{\circ} 11$, Lám. VII ) en un mosaico rectangular de $12 \mathrm{~m}^{2}$ también perfectamente conservado y donde se combinan tres colores, blanco, negro y rojo.

\section{LA PARS RUSTICA}

En lo que respecta a las instalaciones de la explotación agropecuaria de la villa de Almenara, aparte algunos datos de una intervención anterior (Delibes y Moure, 1973, 21-24 y 43-46) y las estructuras identificadas en fotografía aérea que hemos comentado más arriba, se conoce muy poco. En las últimas excavaciones se han descubierto también, al norte y al sur de la residencia señorial, restos de instalaciones muy arrasadas, probablemente relacionadas también con las actividades rústicas de la villa. $\mathrm{Al}$ norte, las evidencias son fondos de mortero de cal y arena de pequeñas balsas (Fig. 1, al este de G), y el fondo de una pileta de mortero hidráulico con moldura de cuarto de círculo (fig. 1, I), tal vez relacionables con la elaboración de vino, el suelo de baldosas de un posible silo (fig. $1, \mathrm{H}$ ) y otras estructuras (fig. 1, F) de difícil interpretación. Al sur, son cimientos de cantos rodados de dos construcciones superpuestas, $\tan$ arrasadas que no se puede precisar su funcionalidad, no obstante, la presencia en ellas de vasijas de almacenamiento alojadas en el suelo de tierra, podría sugerir que se trata de un área de despensa (cella), relacionada con la vivienda. A esa zona deben de pertenecer también las estructuras señaladas con la letra A en la figura 1, igualmente muy destruidas por las labores de arada, al encontrarse, como ellas, muy superficiales, en el punto más alto de la pequeña elevación donde se instaló la mayor parte de la villa.

Quedan aún por excavar el resto de las instalaciones de la explotación agrícola y ganadera de la villa: establos, almacenes, talleres, etc.

\section{CONSIDERACIONES FINALES}

En las viviendas más acomodadas del mundo romano - y ésta lo era-, no hay una clara distinción entre sector privado y público, como tampoco lo había en los palacios europeos hasta el siglo XIX (Wallace-Hadrill, 1988, 94,). Es claro que el peristilo norte centra una zona de recepción y celebraciones. También es claro que en el patio sur la mayor compartimentación de la superficie y por tanto la multiplicidad de espacios más reducidos, agrupados a veces, unida a la mejor orientación en un clima frío como el de esta zona, apuntan a una utilización preferente de ese sector para vivienda. Sin embargo, sus dos grandes salones ( ${ }^{\text {os }} 34$ y 29) demuestran que la vida familiar se desarrollaba concertada con actividades protocolarias de recepción de invitados, etc., sin distinción espacial entre lo familiar y lo público.

En Almenara, en comparación con otras villas hispanas, la variedad de diseño de los espacios de tipo suntuario es notable, se emplean las cuatro variantes conocidas en la planta de oeci y triclinia bajoimperiales: la mas sencilla, ortogonal con cabecera semicircular, la rectangular con cabecera poligonal, la central poligonal y la semicircular lobulada. A ello hay que añadir las plantas triconque y cruciforme biabsidada, presentes en el gran ambiente situado al final del corredor de las termas.

Todo ello pone de manifiesto la multiplicación de espacios para un mismo uso, es decir el derroche deliberado de espacio como muestra de poder social (Wallace-Hadrill, 1988, 92). Las dimensiones -2.500 $\mathrm{m}^{2}$ - de la mansión de la villa de Almenara no son de las mayores conocidas, pero sí son amplias, lo que nos lleva a considerarla un pequeño palacio rural. Son las peculiaridades de su planta, la duplicidad de peristilos, la multiplicación de los espacios de recepción, el trazado de éstos y las amplias termas, dotadas además de un gran ambiente de compleja planta, los que le proporcionan ese carácter. 
En Almenara la multiplicación de salas ceremoniales define el carácter palaciego de la residencia. En ella se duplican los salones de banquete y recepción y se añade una sala triconque que corona un ala del eje longitudinal de los baños, paralelo al del $o e$ cus de cabecera pentagonal. Hay pues, doble duplicación de esos ambientes. La conduplicatio no necesariamente tiene que responder a un uso estacional de los dos espacios más públicos —oecus y triclinio-: al norte exedra de verano (la de cabecera poligonal, $\mathrm{n}^{\circ} 7$ ) y triclinio de invierno (el cuadrangular absidado, $\mathrm{n}^{\circ} 3$ ) y al sur, exedra de invierno, (la octogonal, $\mathrm{n}^{\circ} 34$ ) y excelente triclinio de verano (el ultrasemicircular, $\mathrm{n}^{\circ} 29$ ). Es muy probable que todos fueran de uso polivalente. Todo ello no hace sino reforzar la impresión de que espacios públicos y privados se mezclaban en las casas acomodadas sin una clara distinción zonal. Se puede decir que el sector sur debió de tener un uso más residencial y para recibir invitados o amigos, por ser menos accesible que el septentrional, donde el espacio está mayoritariamente dedicado a la recepción, es decir a los visitantes. Esa explicación parece cuadrar mejor que la suposición de dos posibles unidades familiares diferentes habitando en este solar, como para explicar esa repetición de ambientes propone Smith (1977).

Las reformas realizadas en el balneum de Almenara cuando se amplía el pasillo y se levanta la imponente sala triabsidada. abundan en la idea del carácter simbólico y de prestigio de este sector de la casa, especialmente cuidado por los dueños, ya que en él tenían su escenario también las relaciones sociales. La sala triconque cuyo volumen debía destacar del resto del conjunto funcionaba seguramente como una señal al exterior de la categoría de la vivienda, conforme al concepto latino del decoro debido al alto estatus del dominus, seguramente un clarissimus vir, en cualquier caso, un potentior y personaje destacado de un municipio próximo. Éste sería en principio, hasta que se pueda aclarar el carácter del extenso yacimiento localizado en diversos pagos sobre todo de Olmedo ${ }^{19}$, el caucense.

La parte residencial de la villa de Almenara, construida en la segunda mitad del siglo IV estuvo en uso tal vez estacional, durante tres generaciones al menos. Se hizo, como hemos visto, sobre restos

\footnotetext{
${ }^{19}$ En prospecciones superficiales realizadas en lo años 80 por un equipo de la Universidad de Valladolid, en el marco de un Convenio con la Diputación provincial para realizar el Inventario Arqueológico de la provincia. Tiene en torno a $70 \mathrm{Ha}$ y en él se hallaron materiales desde el siglo I pero sobre todo, bajo-imperiales. Los informes se encuentran en la Delegación Territorial de la Junta de Castilla y León. Agradecemos las informaciones a I. Centeno, miembro del equipo hasta 1999.
}

de una anterior. ¿Tal vez por cambio de dueño? No se puede por ahora saber si la reforma afectó también al resto de las instalaciones. En cualquier caso, la etapa de auge de la villa bajoimperial de Almenara se inscribe entre el último cuarto del siglo IV y el primero del v, es decir en época de Teodosio y Honorio. Así, al espléndido palacio de Armuña (Regueras y del Olmo,1997), y a algún otro, también en tierras caucenses, como el de Aguilafuente, se puede unir el de Almenara, caracterizando en estas tierras el apogeo de ese libro de arquitectura.

\section{BIBLIOGRAFÍA}

BALADO, A., 1987: La secuencia protohistórica del yacimiento de Almenara de Adaja (Valladolid). BSAA LIII; 169-177.

BALIL, A., 1980: No 391 Almenara de Adaja. Arqueologia 79, p.238.

- (1984): № 728. Arqueología 83. Madrid; p. 142.

- (1994) Arte de la época romana. Historia del Arte en Castilla y León. Valladolid (1989), 69124

BALMELLE, C., 2001: Les démeures aristocratiques d'Aquitaine. Societé et culture de l'Antiquité tardive dans le Sud-Ouest de la Gaule. Bordeaux-Paris

DEGBOMONT, J. M., 1984: Hypocaustes. Liêge, 1984.

DELIBES DE CASTRO, G.; MOURE ROMANILLO, J.A., 1973: Excavaciones arqueológicas en la villa romana de Almenara de Adaja (Provincia de Valladolid). Campaña de 1969. NAH, Arqueología (2), 15-50.

DUNBABIN, K. M. D., 1999: «Mosaics of the Greek and Roman World, Cambridge.

ELLIS, S. P., 1991: Power, Architecture and decor: How the late Roman aristocrats appeared to his guest. en A. Leslie (ed.) Roman Art of the private Sphere. New perspectives on the Architecture and decor of the domus, villa and insula. University of Michigan, 75-98.

GARCIA ENTERO, V., 2001: Los balnea de las villae hispanorromanas. Provincia tarraconense. Madrid.

GARCÍA GUINEA, M. A., 1977: Los mosaicos tardorromanos de Quintanilla de la Cueza (Palencia). En Segovia y la Arqueología Romana. Barcelona, 188-189.

GARCÍA MERINO, C.; SÁNCHEZ SIMÓN, M., 2000: Excavaciones en la villa romana de Almenara-Puras (Valladolid): Avance de resultados (I). BSAA LXVII, 99-124. 
HERNÁNDEZ VALVERDE, M., 2000: La intervención en los pavimentos musivos de la villa romana de Almenara de Adaja-Puras (Valladolid). Restaurar la memoria. Actas del Congreso Internacional. ARPA 2000. Valladolid, 439-451.

LUCAS PELLICER, M ${ }^{a}$ R., 1987: La influencia africana en la iconografía equina de la villa de Aguilafuente (Segovia). Cuadernos de Prehistoria de la Universidad Complutense de Madrid 12-13, 219-235.

LUCAS PELLICER, $\mathrm{M}^{\mathrm{a}} \mathrm{R}$; BLASCO BOSQUED, $M^{a}$ C:, 2000: Reconstrucción temporal y socioeconómica de la Torrecilla. En $\mathrm{M}^{\mathrm{a}}$ C.Blasco y $\mathrm{M}^{\mathrm{a}}$ R. Lucas (eds.) El yacimiento romano de la Torrecilla: de villa a tugurium. Madrid.

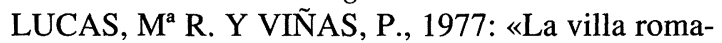
na de Aguilafuente (Segovia)». Segovia y la Arqueologia romana. Barcelona, 239-256.

MAÑANES PÉREZ, T., 1992 La villa romana de Almenara-Puras (Valladolid). Valladolid.

- (1999): El mosaico de Pegaso y las ninfas de la villa romana de Almenara de Adaja-Puras (Valladolid). en J. Lancha (ed): El tiempo en los mosaicos romanos de Hispania iconografía, modos de asociación, contexto histórico y arquitectónico. Actas del Coloquio internacional (Lyon, 29-30 Abril y 1 de mayo de 1993). Anas 11-12, 145154.

NEIRA, M. L.; MAÑANES, T., 1998: Mosaicos romanos de Valladolid. Corpus de mosaicos de España, XI, Madrid.

NIELSEN, I., 1990: Thermae et balnea. Aarhus.

NIETO GALLO, G., 1943: La «villa» romana de Almenara de Adaja (Valladolid). BSAA X, 197-199.
ORTEGO FRÍAS, T., 1957 «La villa romana de Santervás del Burgo (Soria)» NAH III-IV, 169193.

- (1959): La villa romana de Santervás del Burgo (Soria). VI CNA (Oviedo, 1959), 219-228.

- (1961): La villa romana de Santervás del Burgo (Soria). Celtiberia 22,182-202.

- (1965-66): La villa romana de Santervás del Burgo (Soria). AespA, 38-39, 186-187.

- (1977): La villa romana de los Quintanares en el término de Rioseco (Soria). Segovia y la Arqueología romana. Barcelona, 285-292.

REGUERAS GRANDE, F.; DEL OLMO, J., 1997: La villa de los Casares (Armuña, Segovia). Propuestas de lectura. En R. Teja y C. Pérez (eds.) $L a$ Hispania de Teodosio Actas del Congreso Internacional (Segovia, 1955). Salamanca, Vol. 2, 675884.

REGUERAS GRANDE, F.; PEREZ OLMEDO, E., 1997: Mosaicos romanos de la provincia de Salamanca. Salamanca.

SAN NICOLÁS PEDRAZ, Ma P., 1997: Representaciones alegóricas de fuentes y ríos en los mosaicos romanos de Hispania. En $\mathbf{M}^{\mathrm{a}} \mathrm{J}$. Pérex Agorreta (ed): Termalismo antiguo. Madrid, 467-480.

SMITH, J.T., 1978 :Villas as a key to Social Structure. En Malcom Todd (ed.) Studies in the Romano-British Villa. Leicester, 149-185.

- (1982): Villa plans and Social Structure in Britain and Gaul. Caesarodunum 17, 321-326.

TORRES CARRO, M., 1990: Los mosaicos de la Meseta Norte. BSAA, LVI, 223-243.

WALLACE-HADRILL, A., 1988: The Social Structure of the Roman house. BAR 56, 43-97. 